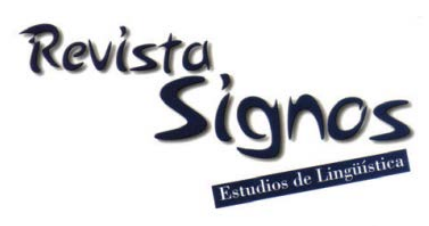

\title{
Cohesión nominal en la narración escrita compuesta por alumnos euskaldunes*
}

\author{
Inés Ma García-Azkoaga \\ UNIVERSIDAD DEL PAÍS VASCO (UPV/EHU) \\ ESPAÑA \\ ines.garciaazkoaga@ehu.eus
}

Noun cohesion in narratives written by basque students

Recibido: 24-IV-2016 / Aceptado: 18-VIII-2017

\section{Resumen}

Este trabajo analiza la cohesión nominal en narraciones escritas en euskera por jóvenes de educación obligatoria (Primaria y Secundaria) y de formación de profesorado. El objetivo es identificar las diferencias que aparecen en cada nivel con la finalidad de aportar datos que permitan a los docentes diseñar intervenciones didácticas más adecuadas para cada nivel educacional. Se estudia un corpus de 80 textos escritos por cuatro grupos de 20 estudiantes cada uno pertenecientes a distintos niveles académicos: $6^{\circ}$ de primaria, $2^{\circ}$ y $4^{\circ}$ de secundaria y primer curso de Formación Universitaria de Profesorado. Todos los textos, 1 por estudiante, son producidos a partir de una misma consigna. Tras un análisis pormenorizado de los procedimientos anafóricos que se utilizan y su relación con el nivel no verbal de las narraciones, se constata que aparecen procedimientos variados y consolidados desde los 11 años; asimismo, las regularidades observadas en la cohesión nominal parecen ser indicativas de las características del propio género textual. Por otro lado, se observa que las dificultades están presentes en todos los grupos y que no hay una progresión continuada de un grupo a otro; vemos, además, que la aparición de unos procedimientos anafóricos u otros no depende tanto de la edad como de las representaciones que tienen los sujetos sobre la situación de comunicación.

Palabras Clave: Cohesión nominal, narración escrita, género textual, anáfora, didáctica de las lenguas. 


\begin{abstract}
This paper analyses the noun cohesion in narratives written in Basque by young students of compulsory education (primary and secondary) and by teacher training. The aim is to identify the differences that appear in each level in order to provide data that allow teachers to design more appropriate didactic resources and interventions for each educational level. A corpus of 80 written texts among four groups of 20 students is studied, being each student from a different academic level: 6th grade of primary school, 2nd and 4th grade of secondary school and first year of Teacher Training Formation. All the texts, 1 per student, are produced based on the same consignment. After a detailed analysis of the anaphoric procedures used and their relation with the non-verbal level of the narrations, it is stated that varied procedures appear and are consolidated from the age of 11 . The observed regularities in the nominal cohesion seem to be indicatives of the characteristics of the textual genre itself. Moreover, it is observed that the difficulties are present in all groups and there is not continuous progression from one group to another. Moreover, it is observed that the emergence of some anaphoric procedures or others do not depend so much on the age as they do on the representations the subjects have among the communicative situation.
\end{abstract}

Key Words: Noun cohesion, written narrative, text genre, anaphora, didactics of languages.

\title{
INTRODUCCIÓN
}

La necesidad de abordar la enseñanza-aprendizaje de las lenguas teniendo en cuenta sus usos sociales está ampliamente reconocida y así viene recogida en muchos currículos educativos. Eso supone que la escuela debe enseñar a sus alumnos a producir y comprender textos orales y escritos de muy diferentes características con el fin de que puedan desarrollar capacidades lingüísticas y comunicativas que les ayuden a desenvolverse en diferentes contextos. Ahora bien, esos textos deben estar adaptados a las necesidades de los alumnos de forma que sean significativos y de utilidad para ellos. En ese sentido, una de las principales cuestiones que se plantea en una didáctica basada en el uso de los textos es la de cómo organizar la progresión temporal de los contendios (Dolz \& Schneuwly, 1997; Nonnon \& Dolz, 2010; Gagnon, 2009) y su evaluación. Como señalan Dolz, Noverraz y Schneuwly (2001), la enseñanza de los textos implica tener en cuenta cuáles son las capacidades que tienen los alumnos antes de la intervención didáctica. Esa producción inicial nos sirve para diagnosticar los saberes que han de ser objeto de enseñanza-aprendizaje y constituyen la base de una evaluación formativa que, además, permite evaluar con rigor los progresos de los alumnos (García-Azkoaga \& Idiazabal, 2015).

Desde ese punto de vista, vamos a centrarnos aquí en la narración escrita a fin de conocer cuáles son las capacidades y dificultades que tienen alumnos y estudiantes de lengua de distintos niveles educativos en lo que respecta a la construcción de la cohesión nominal del texto. Abordamos así el análisis de la cohesión nominal, y más concretamente, el uso de los recursos anafóricos, en narraciones escritas por 
estudiantes de primaria ( $6^{\circ}$ curso), secundaria ( $2^{\circ}$ y $4^{\circ}$ curso) y Formación Universitaria de Profesorado (1er. curso). Se trata en este caso de narraciones escritas en euskera (lengua vasca), si bien el análisis que se plantea puede hacerse extensivo a otras lenguas. Hay que recordar, no obstante, que el euskera, además de ser una lengua ergativa y postpositiva, es también una lengua pro-drop; tal como se señala en Sareko Euskal Gramatika (Gramática Vasca en Red), es una lengua muy rica en lo que se refiere a la concordancia entre el verbo auxiliar y los argumentos, lo que facilita la posibilidad de omitir los pronombres ya que la concordancia queda reflejada en el verbo auxiliar.

En lo que se refiere a las narraciones, el interés por su estudio ha estado presente en muchos investigadores interesados por el desarrollo del lenguaje (Bamberg, 1987; Berman \& Slobin, 1994; García-Soto, 1996; Shiro, 2012). También la didáctica de la lengua se ha interesado por los textos narrativos, tanto en su forma escrita (Hocevar, 2007) como en su forma oral (García-Azkoaga, Idiazabal \& Larringan, 2009). En el caso más específico de la cohesión nominal, tenemos algunos trabajos que se han interesado por la forma en que los niños elaboran la cohesión en textos diferentes (De Weck, 1991) o la muy interesante aportación de Marmy Cusin (2012) que estudia la cohesión nominal en el ámbito de una secuencia de aprendizaje abordando distintos aspectos (semántico, lingüístico y pragmático) del funcionamiento de este mecanismo. Narración y recursos anafóricos para la cohesión han sido estudiados también por Borzone y Silva (2010) que analizando un cuento oral a partir de una secuencia de imágenes observan diferencias en función de la edad de los niños. Asimismo, Borzone, Silva y Benítez (2012) comparan un relato de experiencia personal y un relato a partir de imágenes en adultos letrados y no letrados y concluyen que los no letrados tienen más dificultades en el relato realizado a partir de imágenes. Tenemos, sin embargo, pocos trabajos empíricos que den cuenta de lo que sucede en euskera (Idiazabal, 1994; Ocio, 1998) y, salvo excepciones (García-Azkoaga, 2003), carecemos de trabajos que analicen los mecanismos de cohesión nominal en narraciones escritas por sujetos mayores de 15 años. Por lo que respecta a la cohesión nominal, la entendemos como un mecanismo de textualización (Bronckart, 1996) que permite introducir argumentos y retomarlos a lo largo del texto, labor que se realiza básicamente por medio de anáforas. Pero es que, además, las anáforas, revelan formas de denominación que reflejan las intenciones o los efectos que busca el narrador (García-Azkoaga \& Díaz de Gereñu, 2009) y, por los tanto, las representaciones que aquél tiene sobre la situación de comunicación.

Antes de analizar esas cuestiones, comenzaremos con una breve exposición del marco teórico en el que se inscribe este trabajo y de la forma en que entendemos la cohesión nominal dentro del mismo. Seguidamente, describiremos el procedimiento seguido para recabar los textos objeto de estudio. Nos detendremos después en el análisis de los procedimientos anafóricos que emergen a la hora de cohesionar el texto, 
tras lo cual, nos fijaremos en el contenido de las narraciones a fin de ver cuáles son las representaciones que emergen durante su escritura. Los resultados nos permitirán extraer, finalmente, algunas conclusiones importantes para conocer mejor las capacidades comunicativas de los alumnos y mejorar las intervenciones didácticas.

\section{Marco teórico}

A la hora de producir un texto oral o escrito todos partimos de unos conocimientos previos sobre los comportamientos verbales y comunicativos, sobre las convenciones sociales y sobre los contenidos temáticos, pero es necesario reorganizar esos conocimientos para que la comunicación sea lo más efectiva posible.

Situándonos en el marco del interaccionismos sociodiscursivo, desde el punto de vista del funcionamiento de la actividad verbal y de los textos (Bronckart, 1996, 2013) podemos distinguir un nivel de acción no verbal (o acción general) y un nivel de acción verbal (o acción lingüística). El nivel no verbal abarca las capacidades para adaptar la producción a las características físicas y sociales del contexto comunicativo. Es en ese nivel donde se manifiesta cómo inerpreta el individuo las características contextuales de la situación de comunicación, es decir, las representaciones que hace del contexto en función de los conocimientos, de la experiencia y de las capacidades lingüísticas que haya desarrollado. En el nivel de la acción verbal o acción lingüística, en función de las decisiones que se hayan tomado en el nivel no verbal, se despliegan los mecanismos lingüísticos y discursivos que proporcionarán al texto cohesión, conexión y coherencia. Es en el nivel de la linearización lingüística donde se sitúan los mecanismos de cohesión nominal que queremos analizar en este trabajo. Sirviéndose de estos mecanismos el narrador va proporcionando informaciones adicionales de los personajes a lo largo del texto, actualiza los objetos de discurso a medida que avanza la narración, puede jugar estilísticamente con la denominación de los personajes para construir una representación de los mismos (García-Azkoaga \& Díaz de Gereñu, 2009) o incluso, puede dejar la huella de las representaciones que el propio autor hace sobre los objetos de discurso que va actualizando. Y además, puede enriquecer el texto utilizando un repertorio léxico variado en las retomas y actualizaciones de los personajes y objetos de discurso introducidos en el texto. Es ahí donde los procedimientos anafóricos juegan un papel primordial en la construcción de la cohesión nominal del texto.

Siendo el texto narrativo un género tan habitual y conocido entre nuestros escolares, en este trabajo nos planteamos las siguientes preguntas: ¿Cómo gestionan el tema o los objetos de discurso de sus narraciones los alumnos en la enseñanza obligatoria? ¿Y los universitarios? ¿Podemos pensar que la edad o el nivel académico influyen en la aparición de formas de cohesión más complejas? ¿Se aprecia en todos los grupos una relación entre el nivel no verbal de la acción general y el verbal de los 
elementos lingüísticos que se movilizan para construir la cohesión nominal? Pensamos que la edad o el nivel académico no garantizarán un mayor uso de recursos anafóricos, pero creemos que los sujetos más mayores utilizarán formas de cohesión más elaboradas que mostrarán, además, una forma de adaptación distinta, con un mejor control externo de los textos. Teniendo en cuenta el planteamiento de Bronckart (1996), el aprendizaje de los parámetros socio-subjetivos es largo y complejo; los conocimientos sobre los lugares sociales, las normas y los roles se construyen poco a poco y a lo largo de nuestra vida y son, además, cambiantes; creemos que esos roles se verán reflejados en las narraciones escritas del corpus. Conociendo mejor las características que presenta la cohesión nominal del texto en los distintos niveles educativos comprenderemos mejor el funcionamiento de los textos y contribuiremos a desarrollar herramientas didácticas más acordes con las necesidades de los estudiantes en cada nivel.

\section{Metodología}

Entendemos el texto como una unidad de comunicación que es fruto de la actividad verbal (Bronckart, 1996) y que se produce como un proceso de adopción y adaptación de un género textual según los requisitos de la situación de comunicación. Uno de los niveles que forman parte de la composición interna de esos textos es el de los mecanismos de textualización, entre los cuales se encuentra la cohesión nominal, eje central de este estudio.

\subsection{Procedimiento de recogida del corpus}

Las narraciones fueron realizadas en el contexto académico. En una sesión habitual de clase de lengua, de una hora de duración (tiempo máximo que tenían los sujetos para realizar la tarea), como si se tratara de una actividad académica más, y sin que mediara una intervención didáctica específica anterior sobre la narración, se les planteó a todos los grupos de alumnos la misma situación de comunicación: Escribir una narración de misterio y aventuras para participar, junto con otros colegios, en un concurso de narraciones escritas; la narración elegida sería publicada en una revista local. Para ello, se les proporcionó una consigna en base a la cual tenían que desarrollar la historia: "Dos hermanos (un chico y una chica) van de vacaciones con sus padres a un pueblo pequeño. En el mismo hay una casa misteriosa que esconde un secreto. Los niños vivirán una gran aventura tratando de descubrir lo que sucede en ella".

\subsection{Sujetos}

Son cuatro grupos mixtos (chicos y chicas) de 20 alumnos cada uno: Un grupo de sexto curso de enseñanza primaria (en adelante EP6), de 11 años; un grupo de segundo curso de enseñanza secundaria (ESO2), de 13 años, otro de cuarto curso (ESO4), de 15 años, y estudiantes universitarios de primer curso de formación de 
profesorado de la especialidad de Educación Infantil (M1), de entre 19 y 22 años. En todos los casos, se trata de alumnos bilingües, de procedencia socio-económina similar y de rendimientos académicos similares. Se trata de una muestra con desarrollo típico. Los alumnos no fueron previamente seleccionados y se respetó la configuración propia que cada grupo tenía en su ámbito académico, aunque en el caso de los grupos de primaria y secundaria sí se descartaron los casos más extremos o problemáticos. Las producciones escritas se codificaron para poder ser tratadas de forma anónima y los participantes fueron informados del tratamiento.

Los alumnos no universitarios son alumnos de la misma escuela que estudian íntegramente en euskera. Cada alumno escribe una narración en euskera. Se recogen así 20 textos por cada grupo, uno por alumno. Los textos de los universitarios pertenecen a estudiantes de un mismo grupo que también tienen el euskera como lengua vehicular de sus estudios. Se trata de estudiantes de Magisterio de unos 20 años como media. También en este caso se recopilan 20 narraciones, una por alumno.

Tenemos, pues, un total de 4 grupos y 80 narraciones escritas producidas según la misma consigna.

\subsection{Las unidades de análisis}

Sin olvidar la gran aportación que supuso la obra de Halliday y Hasan (1976) para el conocimiento del texto y de la cohesión en particular, para este trabajo hemos partido del esquema de la arquitectura textual de Bronckart (1996). Desde este punto de vista diferenciaremos conexión y cohesión, y dentro de la cohesión, además, cohesión verbal y cohesión nominal. Aquí, nos fijaremos exclusivamente en la cohesión nominal, mecanismo textual gracias al cual quien produce un texto puede asegurar la continuidad y el desarrollo de la información a lo largo del mismo, y quien lo lee o escucha puede establecer vínculos entre diferentes elementos, de forma que puede relacionar o interpretar coherentemente las informaciones que se dan a lo largo del texto.

La cohesión nominal se realiza básicamente por medio de procedimientos anafóricos. De esta manera, un objeto de discurso o tema puede ser mencionado en diferentes ocasiones y de diferentes formas, y puede estar presente a lo largo o en parte de toda la producción textual. Pero además, durante la narración pueden surgir nuevos objetos de discurso que a su vez pueden ser retomados y actualizados anafóricamente a lo largo del texto. Sin pretender hacer un análisis exhaustivo de todos los elementos susceptibles de intervenir en la cohesión textual, ni de todas las particularidades que rodean a la anáfora, en este trabajo partiremos de una clasificación (García-Azkoaga, 2003) que nos ayudará a identificar algunos de los principales mecanismos implicados en la narración. En primer lugar, realizaremos un estudio formal del texto y de las anáforas para proporcionar algunos datos 
cuantitativos con aplicación de medidas estadísticas. A continuación, abordaremos un análisis cualitativo sobre el contenido de las narraciones.

Para al análisis tendremos en cuenta los siguientes parámetros:

a) Longitud de los textos: Medimos en número total de palabras por cada texto y calculamos el promedio para cada grupo. Si bien esta medida no tiene por qué ser significativa por sí misma, nos aportará una referencia para poder contrastar tanto las diferencias interpersonales como las intergrupales, pero sobre todo, para poder calcular también porcentualmente la aparición de elementos anafóricos en cada grupo.

b) Presencia en cada grupo de los principales procedimientos anafóricos que contribuyen a la cohesión nominal de los textos narrativos: Se identificarán los elementos que se utilizan para retomar anafóricamente los antecedentes y se contabilizarán las retomas. Independiente de que el valor anafórico del nombre propio sea más o menos discutible, también se incluirá éste entre los elementos cohesivos habida cuenta de que es un elemento habitual en la retoma de los personajes de las narraciones y de que, además, puede tener un destacado valor connotativo en las mismas (García-Azkoaga \& Díaz de Gereñu, 2009).

c) Análisis cualitativo de los contenidos de las narraciones de cada grupo poniendo el foco en el tema central de la historia para ver como la acción lingüística está al servicio de la acción general. Es decir, como las decisiones léxicas que se adoptan a la hora de actualizar los temas y dar cohesión al texto, estan relacionadas con los conocimientos del mundo y con las representaciones que el narrador tiene sobre el contexto fisico y social de la situación de comunicación.

\section{Resultados}

\subsection{Longitud de los textos}

Tabla 1. № de palabras por grupo.

\begin{tabular}{|l|l|l|l|l|}
\hline & EP6 & ESO2 & ESO4 & M1 \\
\hline Total palabras & 5080 & 5822 & 5456 & 7203 \\
\hline Promedio & 254 & 291 & 273 & 360 \\
\hline Narración más larga & 459 & 526 & 501 & 529 \\
\hline Narración más corta & 145 & 120 & 124 & 157 \\
\hline Desviación típica, $\sigma$ & 88 & 129 & 110 & 95 \\
\hline
\end{tabular}

Como podemos apreciar en la Tabla 1, el aumento de la longitud de los textos en esos grupos es proporconal al nivel académico salvo en el grupo de ESO4. El coeficiente de correlación de Spearman entre la longitud media de los textos y el nivel académico, con un valor de $\mathrm{r}=0,8$, es positivo y elevado, de lo cual se deduce que la longitud guarda una estrecha relación con el nivel académico. Por otro lado, como se 
puede apreciar por la desviación típica, donde más dispersión se da en la longitud de los textos es en el grupo de ESO2.

\subsection{Elementos de cohesión nominal de las narraciones}

Se han contabilizado los recursos anafóricos más habituales implicados en la narración agrupándolos en anáforas pronominales, nominales, adverbios y nombres propios. Los porcentajes se calculan sobre el total de palabras de las narraciones.

Constatamos que en los 4 grupos aparecen todos los tipos de anáforas y que las nominales son las más utilizadas en todos ellos. Esa mayor utilización respecto a las anáforas pronominales se puede explicar si tenemos en cuenta que el euskera no necesita hacer explícita la referencia personal en forma de pronombre, ya que va marcada en la propia flexión verbal; de ahí las diferencias con autores como De Weck (1991) que observa que en francés en las narraciones de los niños predomina la anáfora pronominal.

No obstante, para conocer si el repertorio de recursos para construir la cohesión nominal del texto es similar en todos los grupos, es necesario ver más en detalle (Tabla 2) cuáles son los procedimientos anafóricos precisos que se movilizan dentro de cada uno. 
Tabla 2. Porcentaje de anáforas en cada grupo.

\begin{tabular}{|c|c|c|c|c|}
\hline $\begin{array}{r}\text { Procedimiento anafórico } \\
\end{array}$ & EP6 & ESO2 & ESO4 & M1 \\
\hline Pronombres personales de $1^{\mathrm{a}}$ y $2^{\mathrm{a}}$ persona & 0,22 & 0,09 & 0,16 & 0,15 \\
\hline Pronombres personales de $3^{\mathrm{a}}$ persona & 0,33 & 0,50 & 0,55 & 0,53 \\
\hline Genitivos (bere anaia -su hermano-...) & 0,57 & 1,15 & 0,81 & 0,85 \\
\hline $\begin{array}{l}\text { Pronombres indefinidos y generalizantes (batzuk, denak - } \\
\text { algunos, todos-...) }\end{array}$ & 0,06 & 0,14 & 0,11 & 0,10 \\
\hline $\begin{array}{l}\text { Pronombres recíprocos (elkarrekin, elkarri, bere burua -juntos, } \\
\text { uno a otro, a si mismo-...) }\end{array}$ & 0,02 & 0,00 & 0,04 & 0,10 \\
\hline Pronombres numerales (Biak -los dos- ...) & 0,14 & 0,40 & 0,44 & 0,42 \\
\hline 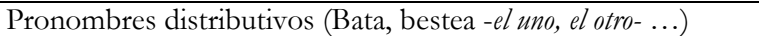 & 0,14 & 0,09 & 0,02 & 0,15 \\
\hline Anáforas pronominales & 1,48 & 2,35 & 2,13 & 2,29 \\
\hline $\begin{array}{l}\text { Repetición del mismo núcleo nominal del antecedente con } \\
\text { determinante artículo (etxe bat - una casa- } \rightarrow \text { etxea -la casa-) }\end{array}$ & 3,62 & 2,54 & 1,59 & 1,96 \\
\hline $\begin{array}{l}\text { Repetición del miso núcleo nominal con determinante } \\
\text { demostrativo (etxe bat -una casa- } \rightarrow \text { etxe hori -esa casa-) }\end{array}$ & 0,75 & 0,76 & 0,68 & 0,83 \\
\hline $\begin{array}{l}\text { Repeticiones parciales o extendidas de un antecedente con } \\
\text { determinante artículo (etxe misteriotsu bat -una casa misteriosa- } \\
\rightarrow \text { etxe zahar misteriotsua - la vieja casa misteriosa-) }\end{array}$ & 0,49 & 0,12 & 1,06 & 1,89 \\
\hline $\begin{array}{l}\text { Sustitución lexical con sintagma nominal con determinante } \\
\text { demostrativo (conceptualización) (animalia bat }- \text { un animal- } \rightarrow \\
\text { txakurra -el perro-) }\end{array}$ & 0,37 & 0,26 & 0,26 & 0,24 \\
\hline $\begin{array}{l}\text { Asociación: sustitución lexical por sintagma nominal con } \\
\text { determinante artículo (etxe bat - una casa- } \rightarrow \text { atea -la puerta-) }\end{array}$ & 2,76 & 3,04 & 3,63 & 3,00 \\
\hline Sinonimia, hiponimia e hiperonomia & 0,20 & 0,17 & 0,02 & 0,35 \\
\hline $\begin{array}{l}\text { Retomas neutras y universales (hori, gauza horiek, guzti hori - } \\
\text { eso, esas cosas, todo eso-...) }\end{array}$ & 0,24 & 0,57 & 0,42 & 0,25 \\
\hline Retoma por nominalización homofónica de una forma verbal & 0,02 & 0,03 & 0,02 & 0,00 \\
\hline Anáforas nominales & 8,44 & 7,49 & 7,68 & 8,51 \\
\hline Adverbios & 0,94 & 1,06 & 1,21 & 1,36 \\
\hline Nombres propios & 2,70 & 1,17 & 2,18 & 2,12 \\
\hline TOTAL & 13,56 & 12,07 & 13,20 & 14,29 \\
\hline
\end{tabular}

Aplicando el método de $c h i^{2}$, con un margen de error de 0,05 y un grado de libertad de 48 al conjunto de los datos de la Tabla 2, obtenemos un valor de $c h i^{2}$ de 4,93. Como el valor de referencia para los valores establecidos es de 65,1654, se puede afirmar que la edad de los sujetos no influye en el número de anáforas que se utilizan.

Observamos que el uso de anáforas pronominales aumenta a partir de ESO2, aunque la diferencia principal radica en el tipo de pronombres que se movilizan en cada grupo. El uso de los pronombres de $1^{\mathrm{a}}$ y $2^{\mathrm{a}}$ persona en las narraciones suele estar ligado sobre todo a fragmentos dialogados que se insertan en la propia narración (ver ejemplo en la Tabla 3). En esos casos, su interpretación anafórica se realiza a través de las informaciones que nos proporciona el contexto lingüístico. Los datos de la Tabla 2 nos indican que, porcentualmente, son los alumnos más jóvenes los que más recurren a esas referencias de segunda persona; puede ser debido a que a algunos alumnos les resulta más fácil utilizar el estilo directo que el estilo indirecto, por lo que construyen gran parte de la narración de forma dialogada. En los demás grupos también aparece este uso anafórico, pero los diálogos se introducen de forma más puntual, para crear 
tensión narrativa dando voz a los personajes, lo que, por otro lado, indica un mayor control sobre el propio género textual.

Tabla 3. Ejemplos de fragmentos dialogados.

(1) Behin batean $[. .$.$] honela esan zion alabak amari:$ - Ama, berria ezagutzera joan al gaitezke?

-Bai, noski, baina Jone, ondo zaindu zure anai Aitor galdu ez dadin.

-Bai ama utzi nire esku. Bazkal ordurako bueltan izango gara.

-Geroarte.

-Bai, agur.

Horrela, herria ezagutzera joan ziren.

(Una vez [...] le dijo así la hija a la madre:

-Mamá, podemos ir a conocer el pueblo?

-Sí, pos supuesto, pero Jone, cuida bien a tur hermano Aitor para que no se pierda.

-Sí mamá, déjalo de mi cuenta. Estaremos de vuelta para la hora de comer.

-Hasta luego.

-Sí, adiós.

Así, fueron a conocer el pueblo.) (EP6-8 )
(2) Biak garrasike eta oibuka hasi ziren:

- Ama, ama, lagundu! Aita! hemen gaude!

Aqkenean argiak piz̧tu ziren eta bara non ikusten duten norbait beraiengana etortzen [...] Beraiengana zetorren irudiak esan zien:

-Nor zarete zuek? Nola ausartu zarete bona etortzen?.

Peru eta Maddik eqin zuten ezer esan.

-Ab! Noski. Zuek hemen inguruan bizi zarete udaran!

(Los dos comenzaron a gritar:

-Mamá, mamá, jayúdanos! ¡Papá! ¡Estamos aquí!

Finalmente se encendieron las luces y he ahí que ven acercarse a alguien [...] La figura que iba hacia ellos les dijo:

-¿Quiénes sois? ¿Cómo os atrevéis a venir aquí?

Peru y Maddi no podían decir nada.

-¡Ah, claro! ¡Vosotros vivis por aqui durante el verano!) (M1-9)

Los pronombres personales de tercera persona junto con los genitivos son los más utilizados; el uso de indefinidos y numerales parece presentar mayor dificultad para los escolares más jóvenes (EP6, $6^{\circ}$ primaria). Tanto en primaria como en secundaria son excepcionales los pronombres recíprocos y en algunos casos (ESO2 y ESO4) también los distributivos. En general, parece que el uso de este tipo de pronombres, que podían ser esperables teniendo en cuenta que tenemos como protagonistas a una pareja de hermanos, supone mayor dificultad, o que cuando menos, es fácilmente sustituible por otras formas de referencia personal o de designación más accesibles en el repertorio lingüístico de los sujetos, como son los pronombres de tercera persona y los genitivos.

Si bien las diferencias no son significativas, el uso de anáforas nominales disminuye en ESO2 y ESO4 y vuelve a recuperarse en el caso de los estudiantes más mayores (M1). Una de las instrucciones que frecuentemente se dan en la escuela es la de evitar repeticiones; la influencia de esta instrucción y el mejor control sobre el uso de las formas adverbiales con valor anafórico y sobre algunos pronombres podría influir en el descenso observado. Por otro lado, relacionamos el repunte en M1 con la representación que hacen los sujetos de la situación de comunicación como explicaremos más adelante.

No obstante, si nos fijamos en detalle en las anáforas nominales que se utilizan, vemos que las formas que incorporan elementos atributivos (repeticiones extendidas), 
están ya presentes en los estudiantes más jóvenes. Las fluctuaciones que se observan en ESO2 y ESO4 podrían explicarse por la frecuencia con la que se usan en esos grupos las formas pronominales, las retomas con determinante y los adverbios, siendo, habitual encontrar este tipo de cadenas: 'Una casa vieja, sucia y terrorífica' $\rightarrow$ 'dentro de la casa' $\rightarrow$ 'de esa casa'. Esas retomas no tienen como función únicamente hacer referencia a algo ya mencionado, sino que sirven para construir la escena de misterio.

Respecto a las anáforas conceptuales, cuantitativamente no varían mucho de un grupo a otro; puede ser debido a que la conceptualización, por requerir un control del léxico y unos recursos cognitivos más amplios y específicos, sigue siendo una habilidad lingüística compleja y poco desarrollada aún en los alumnos más mayores. Esa es, precisamente, una de las dificultades ya apuntadas por Descombes-Dénervaud y Jespersen (1992) y por García-Azkoaga e Idiazabal (2003) en sus trabajos. No obstante, el hecho de que su porcentaje sea bastante parecido en todos los grupos, y que su porcentaje esté por debajo de las repeticiones y de otros tipos de sustitución léxica, nos puede indicar que se trata de una característica propia del texto narrativo. No obstante, cabe también una explicación relacionada con la dimensión no verbal del texto, pues la forma en que los sujetos de M1 representan la situación de comunicación les puede llevar a utilizar recursos cohesivos que consideran más comprensibles para los receptores del texto.

Las anáforas asociativas ocupan un lugar muy destacado en todos los grupos aún cuando su aparición varía un poco de uno a otro. Su frecuencia en las narraciones es previsible si tenemos en cuenta que los objetos de discurso que se tematizan son frecuentemente elementos tópicos y conocidos que propician las proyecciones semánticas y, por lo tanto, la aparición de anáforas indirectas ('vacaciones' $\rightarrow$ 'playa; una casa misteriosa' $\rightarrow$ 'las escaleras / la ventana / la puerta...'). Gracias a este tipo de anáforas se amplía el mundo referencial y ello contribuye a construir el escenario de los acontecimientos.

Respecto a los adverbios, vemos que si bien su porcentaje es algo inferior, también están presentes en las narraciones de los más jóvenes (EP6).

En lo que se refiere a los nombres propios, también es un recurso muy utilizado y si bien disminuye en ESO2, vuelve a repuntar en ESO4 y en M1. Por otro lado, observamos que en los textos de los más jóvenes tanto los nombres de los lugares (Pensilvania, New York, Moscú, Holanda...) como los de los personajes son portadores de más connotaciones que en el grupo M1 o, cuando menos, son más originales.

(3) "Bazen behin Bixenta izeneko neskatila handi eta osasuntsu bat, Patxi izeneko mutil bat anaitzat zeukala. Bi anai-arrebak baserritarrak ziren [...] pausuak eta oibuak entzun ziren goiko pisuan." (Érase una vez una chica grande y sana llamada Bixenta, que tenía 
por hermano un chico llamado Patxi. Los dos hermanos eran campesinos [...] se oyeron pasos y gritos en el piso superior.) (ESO4-4)

En el ejemplo (3) el hecho de que los personajes se llamen Bixenta y Patxi, nombres más típicos de una tradición anterior que nos retrotrae al mundo rural y a personajes fuertes y saludables, transmite la sensación de capacidad para hacer frente a los riesgos que se les avecinan. Veamos algunos ejemplos más:

(4) "Nerriberritz-a joan ginen. Inork ez du herri hau ezagutzen". (Fuimos a Neriberritz. Nadie conoce ese pueblo.) (ESO2-2)

(5) "Shamirak [...] Ile hori eta luzea zeukan, beti kopeta batean bildua zeramana. Begi urdin koloretsuak zituen, politak eta biziro baundiak. Obikoa zen bere ezpain ezti haietan barretxo bat zintzilikaturik ikustea". (Shamira [...] tenía el pelo rubio y largo, recogido siempre en una coleta. Tenía ojos azules, bonitos y grandes. Era habitual ver una sonrisa colgada en aquellos dulces labios.) (ESO2-5)

(6) "Sotela familia, aita, ama eta bi anai-arrebak konposatzen zuten [...] Japa eta J.P.". (La familia Sotela estaba compuesta por el padre, la madre y dos hermanos [...] Japa y J.P.) (ESO4-2)

Los nombres de ciudades lejanas, así como el nombre inventado, Neriberritz, inducen al misterio de lo desconocido; Shamira nos trae lo exótico, supone la utilización de un nombre poco habitual en nuestra cultura para introducir un personaje con unas cualidades especiales; Japa y J.P., nombres inventados, nos sitúan en la ficción.

En el grupo M1 solo encontramos nombres de persona habituales en nuestra cultura, especialmente entre la juventud y la infancia: Amaia, Mikel, Perú, Harriet, Ane, Markel... Los nombres de los lugares donde se sitúa la acción se refieren a lugares vacacionales habituales entre los habitantes de nuestra comunidad: Haro, Tudela, Navarra, Peñíscola, Ávila, La Rioja... y muy pocas veces la acción de sitúa en un lugar de nombre indeterminado ("fueron a un pequeño pueblo a una casa que estaba en el monte" -M1-5-) o inventado ("llegaron [...] a Netxo" -M1-7-).

Así, las formas de denominación y las elecciones léxicas que se realizan para actualizar los antecedentes son indicativas del efecto que el narrador quiere producir en el lector $y$, por lo tanto, de la forma en que representa la situación de comunicación.

\subsection{Análisis del contenido}

Decíamos que el nivel no verbal atañe a cómo representa el sujeto la situación de comunicación, es decir, básicamente, a cómo imagina que tiene que ser su mensaje en función de lo que debe comunicar y a quién debe comunicar. Los parámetros 
contextuales condicionarán el resultado final, pues las elecciones y decisiones que el sujeto toma en función de la representación que se hace de ese contexto, así como los conocimientos y las capacidades desarrolladas, dejarán su huella en la producción textual.

Analizados todos los textos, constatamos que todos los sujetos sin excepción han optado por el género textual adecuado para el fin comunicativo que se les planteó. Producen un texto monologal, que es autónomo con respecto al acto de producción porque no contiene elementos lingüísticos que aludan al productor del texto, y con un anclaje discursivo disjunto, es decir, situado en un tiempo pasado y distinto al de la situación de comunicación.

Todas las narraciones presentan, además, una estructura canónica en la que están presentes la situación inicial, la complicación, las acciones, la resolución y el desenlace.

Además, todas las narraciones siguen la consigna e incorporan al relato el lugar donde sucederán los acontecimientos (una casa misteriosa), y los personajes principales indicados (dos hermanos).

No obstante, vemos que a pesar de que todos parten de la misma consigna, con la misma situación y personajes, y además, con la misma base de orientación genérica, las historias que cuentan son muy distintas y se nutren de experiencias personales diferentes. Hay una dimensión experiencial básica relacionada con los hábitos y formas de vida propias de los sujetos (los lugares y formas de pasar las vacaciones, por ejemplo); una dimensión lingüística ligada a los conocimientos adquiridos en esa materia (léxicos, gramaticales, morfosintácticos, literarios, longitud de las narraciones, etc.) que reflejan, entre otras cosas, las representaciones que hacen los sujetos de la situación de comunicación. Hemos visto que en función de esas representaciones algunos sujetos introducen nombre propios con cierta connotación de misterio o exotismo que pueden reflejar la manifestación de unas destrezas discursivas acordes con el género requerido, y que parten de lo que han aprendido a través de otras lecturas o de lo que han visto en el cine y en la televisión. En las narraciones se manifiestan también los gustos particulares de los sujetos sobre el tipo de narración que les gusta, más o menos trágica, más o menos fantástica, con final feliz o con final fatal, etc.

Los sujetos de los grupos de EP y ESO se centran más en la historia que quieren contar y no tanto en para quien la quieren o deben contar; cuentan lo que les gusta y lo que les gustaría oír; se autorrepresentan en la situación de comunicación desarrollando argumentos truculentos, trágicos, fantasiosos, mágicos...

(7) "Ander kuadro bat ikutu zuen eta bide izkutu bat zegoen eta bukaeran diru asko zegoen eta gure abenturazaleek ikusi zuten dirua bankoari ostutakoa zela eta guardia zibilekoei abisatu zuten. Fama eduki genuen eta penarekin itzuli ginen". (Ander tocó un cuadro y había un 
camino escondido y al final había mucho dinero y nuestros aventureros vieron que era dinero robado al banco y avisaron a la guardia civil. Tuvimos fama y volvimos con pena.) (EP6-3)

(8) "Halako baten, lurra zabaldu eta txirrista luze batetik behera jaitsi ginen. Laborategi itxurako bat zegoen, gizaki zati gurtiak poteetan sarturik. [...] Ainhoak sekulako ausardiaz, lepoan bozka egin zion zakurrari. Egun bartatik aurrera, arriskuan dagoen bakoitzean, edo beldur den bakoitzean begiak horitu, letaginak hasi eta aldatzen hasten da". (En una de esas, se abrió el suelo y bajamos por un largo tobogán. Había una especie de laboratorio, todos los trozos de cuerpo humano metidos en botes [...] Ainhoa con increíble valentía, le mordió al perro en el cuello. Desde aquel día, cada vez que está en peligro o tiene miedo, se le ponen los ojos amarillos, le crecen los colmillos y empieza a cambiar.) (ESO2-2)

(9) "Beren gurasoek, [...] desagertu egin ziren [...] zerra afilatu batean bere amaren pijama zegoen bere aitarenarekin batera odol markekin. Aurrerago, bere aitaren ilea ikusi zuten, korrika abiatu ziren eta konturatu ziren bere aitaren burua moztuta zegoela [...] oso beldurtuta bizi izan ziren handik aurrera beraien osabekin eta izebekin”. (Sus padres [...] desaparecieron [...] en una sierra afilada estaba el pijama de su madre junto con el de su padre con marcas de sangre. Más adelante, vieron el pelo de su padre, se dirigieron corriendo y se dieron cuenta que la cabeza de su padre estaba cortada [...] desde entonces vivieron muy asustados con sus tíos.) (ESO2-14)

En las narraciones de los más mayores (M1) la adaptación se realiza teniendo muy en cuenta al interlocutor o al receptor del mensaje; asumen una representación comunicativa ligada al rol profesional que van a desarrollar como enseñantes de Educación Infantil; escriben cuentos para niños, políticamente correctos, y con final feliz la mayoría de las veces. Esa adaptación se traduce también, entre otras cosas, en el tipo de nombres de persona y lugar que eligen, todos ellos muy familiares y conocidos; y en el comedido uso de las escenas de miedo.

(10) "Ganbarako atea ireki eta bi begi handi hurbiltzen ikusi quituqten baina amak makilakin erasotzerakoan halako garraisi berezi bat entzun zuten. Argia piztu eta hantxe zegoen hontza argiaren azpian [...] Lotara zetorren gaueko lagun ezezaguna zuten etxean?' (Se abrió la puerta del camarote y vieron acercarse dos grandes ojos, pero al atacarle su madre con un palo se oyó un grito. Encendieron la luz y allá estaba el búho bajo la luz [...] tenían en casa un desconocido nocturno que venía a dormir.) (M1-2)

Por otro lado, la forma de representar la situación de comunicación se refleja también en los títulos que se eligen: Etxe misteriotsua, Oporrak, Jan egin zituzten, Guraso galduak, Hilketak, Opor zorigaiztoak (La casa misteriosa, Las vacaciones, Se los comieron, Los padres perdidos, Los asesinatos, Vacaciones desgraciadas)... En el caso del grupo M1 tan solo dos sujetos ponen título a sus narraciones y lo hacen poniendo 
Etxe misteriotsua (La casa misteriosa). El resto no pone nada o simplemente lo llama 'narración', o 'cuento', lo que denota que los alumnos más mayores asumen la consigna como una tarea escolar requerida por el profesor, y que además parece que lo que creen que espera el profesor es una narración dirigida a los futuros alumnos de estos estudiantes de magisterio, aunque no se les ha dado esa instrucción.

Finalmente, se aprecia que las narraciones de los estudiantes más mayores (M1) no sólo son más largas, sino que también son discursivamente más elaboradas, por ejemplo, a la hora de crear el misterio antes de nombrarlo:

(11) "Herriko sarreran betidanik atentzioa deitu izan zien etxe bat zegoen. Lehen etxea zen eta berriko zentrutik aparte xamar zegoen. Etxearen paretak landare igokariek estaltzen zituzten, bertan ez zen inor bizi eta gainera batere zaindu gabe zegoen. [...] etxe misteriotsua aztertzeko asmoa zerabilten buruan". (En la entrada del pueblo había una casa que siempre les llamaba la atención. Era la primera casa y quedaba un poco apartada del centro. Las paredes de la casa estaban cubiertas por plantas trepadoras, en ella no vivía nadie y estaba sin cuidar [...] estaban dando vueltas a la idea de examinar la casa misteriosa.) (M1-1)

Desde la primera mención de la casa, queda patente que no se trata de una casa cualquiera, sino que tiene algo especial. Poco a poco, a través de la descripción (llamar la atención, alejada del centro, paredes cubiertas de plantas, descuidada), se van creando las condiciones para llegar a la casa misteriosa. El misterio se induce antes de hacerlo explícito, creando mayor tensión en la narración. De esa manera, se va construyendo la cohesión textual no solo por medio de las retomas anafóricas sino también por medio de otros elementos más ligados a la modalización.

\section{CONCLUSIONES}

Constatamos que ya desde los 11 años el sistema referencial está bien establecido y que los procedimientos anafóricos, tanto pronominales como nominales, son muy variados, aunque por el hecho de tratarse de una lengua pro-drop en euskera serán más abundantes las anáforas nominales.

También se constata que a mayor nivel académico los textos tienden a ser más largos, pero que el incremento de anáforas no sigue la misma pauta, pues baja en ESO2 para crecer un poco en ESO4 y aumentar otra vez en los estudiantes más mayores (M1), que son quienes porcentualmente utilizan más anáforas. Podemos explicar la disminución que se produce en ESO por la disminución de las repeticiones idénticas y tal vez por el aprendizaje de otros recursos más productivos para la cohesión de la narración como los pronombres numerales y los adverbios, pero no obstante, no encontramos una explicación satisfactoria para la tendencia que se aprecia en ESO2. En el caso de las anáforas pronominales y de los adverbios hay una tendencia clara a ser más utilizados por los sujetos más mayores, pero en el caso de las 
anáforas nominales, no sucede lo mismo; podemos explicarlo por el hecho de que los más jóvenes utilizan más las repeticiones idénticas. En cuanto al uso de los nombres propios, hemos visto que no es sólo cosa de los más jóvenes y que dependen también de la intencionalidad y de las funciones que las denominaciones asumen en el texto.

Por otro lado, vemos que la referenciación deíctica se aprende pronto y permanece sin grandes cambios en todas las etapas estudiadas. En cuanto a las formas de retoma neutras, si bien son más habituales en los grupos de ESO, no se aprecia de forma clara y evidente que su rendimiento esté relacionado con la falta de otro tipo de estrategias para la retoma del antecedente.

El bajo porcentaje de anáforas conceptuales y el tan alto de anáforas asociativas en todos los grupos puede ser interpretado como un indicador de las características cohesivas del propio género textual.

No obstante, si bien hemos podido identificar esas regularidades, vemos que el texto es una entidad compleja y que para poder explicar el funcionamiento de la cohesión nominal con todo detalle habría que tener en cuenta la configuración individual que presenta cada texto.

En lo que respecta a la relación entre el nivel de la acción no verbal y el de la acción verbal o lingüística, vemos que si bien el nivel académico permite optar a un repertorio más amplio de procedimientos anafóricos, el uso de los mismos no viene determinado directamente por la edad o por el nivel académico que están cursando los alumnos, sino por las relaciones que existen entre el nivel verbal y el no verbal, pues tanto las representaciones que hacen los sujetos, las posturas discursivas que adoptan en función de esas representaciones, como las formas de los conocimientos y experiencias que tienen influyen en la forma de gestionar el texto y en este caso, más concretamente, la cohesión nominal. Si en la consigna hubiéramos incluido alguna instrucción en el sentido de que había que contar un cuento para niños, podríamos deducir de los resultados que los más mayores tienen una mayor capacidad de abstracción y por lo tanto de gestionar el texto de forma más global, pero en este caso pensamos que ha influido más la representación de la situación de comunicación y la asunción por parte de los mayores de su futuro rol profesional.

No obstante, esa capacidad no deja de ser un indicativo del buen control externo de la narración. Así pues, terminaremos subrayando, sobre todo cara a los profesores en ejercicio y a los futuros profesores de lengua, algunas cuestiones: Por un lado, la importancia que tiene comprender el papel que juega la situación de comunicación en la actividad verbal, no solo en el proceso de la elección del género textual adecuado, sino también en cómo condicionan o afectan las representaciones de esa situación de comunicación a los mecanismos de textualización que se utilizan y a las configuraciones textuales que se generan, dicho de otra manera, comprender que las 
elecciones lingüísticas que realizamos no son arbitrarias sino que, en definitiva, están al servicio de la acción general.

Por otro lado, hay que subrayar que una buena explicitación de la consigna es esencial a la hora de plantear la producción de un texto pues ello condicionará en parte los mecanismos lingüísticos y discursivos que el productor de un texto pondrá en marcha para la consecución de su objetivo comunicativo. Finalmente, si bien la narración se revela como un género textual muy adecuado para trabajar la cohesión nominal por la variedad de recursos utilizables, parece pertinente recordar que ese mecanismo de textualización (con todas sus peculiaridades y en función de su grado de complejidad) debe ser objeto de estudio en los diferentes niveles educativos no solo a través de la narración sino también a través de genéros diferentes y más complejos cada vez que permitan mostrar funcionamientos anafóricos y de cohesión nominal también diferentes y más complejos; en ese sentido, coincidimos con De Pietro y Schneuwly (2003) cuando nos recuerdan que el modelo didáctico de los géneros textuales nos permite tener en cuenta tanto la situación de comunicación en la que se desarrolla la actividad verbal, como la infraestructura de los textos y las unidades lingüísticas que contienen.

Creemos que los resultados de este trabajo pueden servir de ayuda para conocer cuáles son los aprendizajes sobre la narración y sobre la cohesión nominal en particular que merece la pena abordar en la escritura de textos narrativos en cada nivel, aunque tampoco hay que olvidar otros aspectos que no hemos abordado en este trabajo y que deberían de ser tenidos en cuenta a la hora de diseñar una intervención didáctica, como por ejemplo, un análisis más pormenorizado del tratamiento didáctico de las dimensiones pragmáticas, semánticas y gramaticales de las unidades que intervienen en la cohesión nominal. En ese sentido, el trabajo de Marmy Cusin (2012) nos ofrece muy interesantes pistas para un estudio más a fondo de la didáctica de la cohesión nominal, por lo que sería interesante complementar el estudio que aquí se presenta con la observación del trabajo que los docentes realizan en clase y con el análisis de los materiales didácticos que se emplean en las aulas.

\section{REFERENCIAS BIBLIOGRÁFICAS}

Bamberg, M. (1987). The acquisition of narratives. Berlin: Mouton de Gruyter.

Berman, R. \& Slobin, D.-I. (1994). Relating events in narrative: A crosslinguistic developmental study. Hillsdale, Nueva Jersey: Lawrence Erlbaum.

Bronckart, J.-P. (1996). Activité langagière, textes et discours. Pour un interaccionisme sociodiscoursif. Lausana: Delachaux-Niestlé. [Traducción al castellano: Actividad verbal, textos y discursos. Salamanca: Infancia y Aprendizaje, 2004.] 
Bronckart, J.-P. (2013). Una didáctica de las lenguas para una enseñanza bilingüe. En J. Dolz \& I. Idiazabal (Eds.), Enseñar (Lenguas) en contextos multilingües (pp. 31 50). Bilbao: UPV/EHU.

Borzone, A. M. \& Silva, M. L. (2010). De las imágenes al texto: Focalización y uso de recursos anafóricos en relatos de niños y jóvenes. Summa Psicológica UST, 7(1), 105-120.

Borzone, A. M., Silva, M. L. \& Benítez, M. E. (2012). La producción de discurso narrativo en jóvenes y adultos letrados e iletrados [en línea]. Disponible en: https://www.researchgate.net/profile/Maria_Silva57/publication/256475592 _La_produccion_de_discurso_narrativo_en_jovenes_y_adultos_letrados_e_il etrados/links/02e7e5350146fcd2f9000000.pdf

De Pietro, J.-F. \& Schneuwly, B. (2003). Le modèle didactique du genre: Un concept de l'ingénierie didactique. Les Cahiers Théodile, 3, 27-52.

De Weck, G. (1991). La cohésion dans les textes d'enfants. París: Delachaux et Niestlé.

Descombes-Dénervaud, M. \& Jespersen, J. (1992). L’anaphore conceptuelle dans l'argumentation écrit. Pratiques, 73, 465-477.

Dolz, J. \& Schneuwly, B. (1997). Géneros y progresión en expresión oral y escrita. Elementos de reflexión a partir de una experiencia realizada en la Suiza francófona. Textos de Didáctica de la Lengua y de la Literatura, 11, 77-98.

Dolz, J., Noverraz, M. \& Schneuwly, B. (2001). Séquences didactiques pour l'oral et pour l'écrit. Notes méthodologiques. Bruxelles: De Boeck.

Gagnon, R. (2009). Quelle progression pour l'argumentation orale en classe de français? En R. Bergeron, G. Plessis-Bélair \& L. Lafontaine (Eds.), La place des savoirs oraux dans le contexte scolaire d'aujourd'bui (pp. 175-197). Quebec: Presses de l'Université de Québec.

García-Azkoaga, I.-M. (2003). Kohesio Anaforikoa hiru testu generotan. Adinaren araberako garapenaren azterketa. Bilbao: Universidad del País Vasco.

García-Azkoaga, I.-M. \& Idiazabal, I. (2003). La cohesión nominale dans les narrations d'écoliers bilingües basque-espagnols. Lidil, 27, 75-87.

García-Azkoaga, I.-M. \& Díaz de Gereñu, L. (2009). Ahozko narratibotasuna interakzionismoaren argitara: Kohesio-mekanismoek esaten digutena. Euskera, 2(54), 723- 770 .

García-Azkoaga, I.-M. \& Idiazabal, I. (2015). Para una ingeniería didáctica de la educación plurilingüe. Bilbao: Servicio editorial de la UPV/EHU. 
García-Azkoaga I.-M., Idiazabal, I. \& Larringan L.-M. (2009). Contar el mismo cuento a los 5 y a los 8 años. Una explicación desde la perspectiva del interaccionismo sociodiscursivo. Revista de Estudos/Linguisticos Linguistic Studies, 3, 211-226.

García-Soto, X.-R. (1996). Era unha vez. un neno... Santiago de Compostela: Sotelo Blanco.

Halliday, M. A. K. \& Hasan, R. (1976). Cohesion in English. Londres: Longman.

Hocevar, S. (2007). Enseñar a escribir textos narrativos. Diseño de una secuencia didáctica. Revista Lectura y Vida, 28, 4, 50-60.

Idiazabal, I. (1994). Elementos de cohesión y conexión en las primeras fases de la adquisición del lenguaje. Análisis de la producción verbal de un niño vascohispanófono. En J. Meisel (Ed.), La adquisición del vasco y del castellano en niños bilingües (pp. 35-68). Madrid-Franckfurt: Vervuert-Iberoamericana.

Marmy Cusin, V. M. F. (2012). Développer et comprendre des pratiques d'enseignement de la grammaire intégrées à la production textuelle: Entre les dires et les faires. Tesis doctoral, Universidad de Ginebra, Suiza.

Nonnon, E. \& Dolz, J. (Eds.) (2010). La notion de progression dans la pratique et la réflexion sur la langue de l'école au collège. Repères, 41.

Ocio, B. (1998). Haurren narrazio-testuetatik bilduak. En I. Idiazabal \& L.-M. Larringan (Eds.), Koherentiia, kohesioa eta konexioa: Testuratze baliabideak. Hizkuntzaren azterketa eta irakaskuntza (pp. 105-118). Vitoria-Gasteiz: Universidad del País Vasco (UPV/EHU) \& Diputación Foral de Álava.

Shiro, M. (2012). El desarrollo de los géneros en el habla infantil: El caso de la narración. En M. Shiro, P. Charaudeau \& L. Granato (Eds.), Los géneros discursivos desde múltiples perspectivas (pp. 249-278). Madrid-Franckfurt: Vervuert Iberoamericana.

\section{AGRADECIMIENTOS}

* Esta investigación se ha realizado dentro del proyecto número FFI2012-37884C03-01 subvencionado por el Gobierno español y el proyecto número IT-983-16 subvencionado por el Gobierno vasco. 